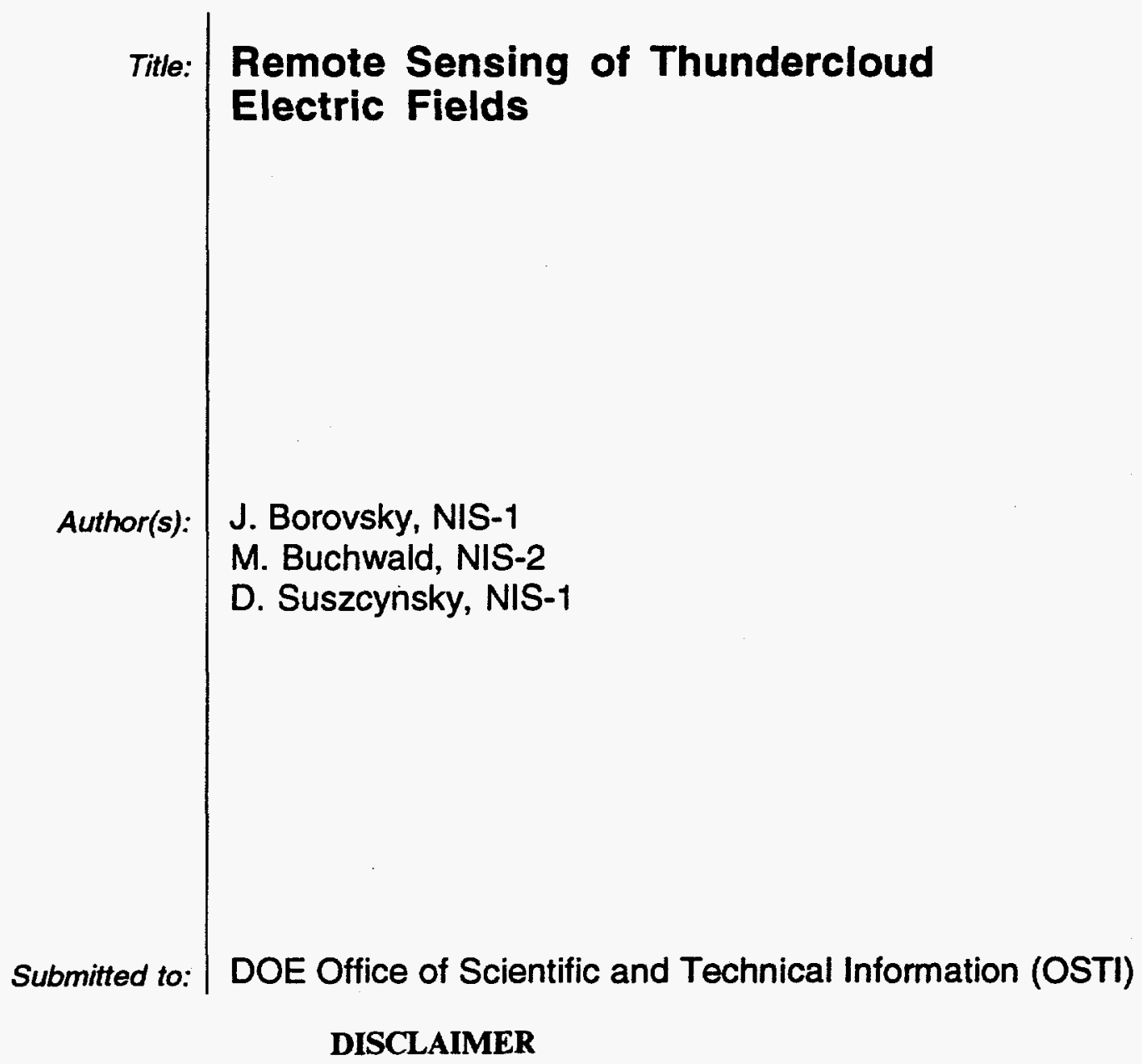

This report was prepared as an account of work sponsored by an agency of the United States Government. Neither the United States Government nor any agency thereof, nor any of their employees, makes any warranty, express or implied, or assumes any legal liability or responsibility for the accuracy, completeness, or usefulness of any information, apparatus, product, or process disclosed, or represents that its use would not infringe privately owned rights. Reference herein to any specific commercial product, process, or service by trade name, trademark. manufacturer, or otherwise does not necessarily constitute or imply its endorsement, recommendation, or favoring by the United States Government or any agency thereof. The views and opinions of authors expressed herein do not necessarily state or reflect those of the United States Government or any agency thereof.

Los Alamos National Laboratory, an affimative action/equal opportunity employer, is operated by the University of Callfomta for the U.S. Department of Energy under contract W-7405-ENG-36. By acceptance of this article, the publisher recognizes that the U.S. Government retains a nonexctusive, royaltyfree ficense to publish or reproduce the published form of this contribution, or to allow others to do so, for U.S. Government purposes. Los Alamos National Laboratory requests that the publisher identify this anticle as work performed under the auspices of the U.S. Department of Energy. Los Alarnos National Laboratory strongly supports academic freedom and a researcher's right to publish; as an institution, however, the Laboratory does not encorse the viempoint of a publication or guarantee its technical correctness. 


\section{DISCLAMIER}

Portions of this document may be illegible in electronic image products. Images are produced from the best available original document. 


\title{
Remote Sensing of Thundercloud Electric Fields
}

\author{
Joe Borovsky, Mel Buchwald, and Dave Suszcynsky
}

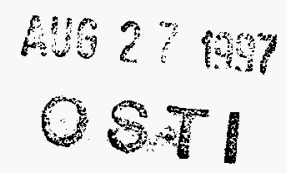

\begin{abstract}
This is the final report of a three-year, Laboratory-Directed Research and Development project at the Los Alamos National Laboratory (LANL). Theoretical and experimental work was performed on the emission of photons from the air within and above thunderclouds and within lightning channels. Predictions were made of the telltale emissions from ionized nitrogen molecules and these emissions were recorded. The measurements will be utilized to help to understand the nature of thundercloud-produced airglow.
\end{abstract}

\section{Background and Research Objectives}

The purpose of this LDRD project is to explore the information that can be gathered by examining 3914- $\AA$ emission from thunderclouds and lightning. The $3914-\AA$ line emission from air is an indicator of the presence of energetic electrons in the air. For thunderclouds, enhanced $3914-\AA$ emission is expected to occur from regions where the thundercloud electric fields are strong enough to accelerate cosmic-ray secondary electrons beyond their $\mathrm{dE} / \mathrm{dx}$ deceleration. For lightning, the emission of $3914-\AA$ photons would be an indicator that energetic electrons are produced in the lightning discharge.

\section{Importance to LANL's Science and Technology Base and National R\&D Needs}

Los Alamos National Laboratory has been acting to develop a research effort in atmospheric electricity to support its $R \& D$ efforts in treaty verification technology and NASA-funded technology. Knowledge about the presence of anomalous amounts of energetic electrons in the atmosphere is important for the understanding of natural radio emissions, for the understanding of atmospheric chemistry, and for the understanding of the global electrical circuit.

\section{Scientific Approach and Accomplishments}

This project has a theoretical and an experimental aspect. The theoretical aspect is

\footnotetext{
*Principal Investigaror, E-mail: jborovsky@lanl.gov
} 
focused on predicting the optical emissions from thunderclouds and from lightning under various assumptions about the physical processes acting in these two regions. For thunderclouds the emissions are calculated for the assumption of a measured bath of cosmic-ray-produced energetic secondary electrons in a strong, large-scale electric field. For lightning the calculations involve estimating the amount of energy dissipated in lighting strokes to obtain optical-emission efficiencies from measured optical emissions. The theoretical aspect is focused on detecting 3914- $\AA$ emissions above background levels with the use of dual photometers optically filtered near $3914 \AA$.

The temporal profiles of lightning emission in the region around $3914 \AA$ were obtained with the dual photometers. Owing to the narrowness of the optical filtering used on the photometers, lightning signatures in daylight were obtained in addition to signatures in darkness. Near $3914 \AA$, the emission profile of the lightning discharges was repeatedly found to be flat. The time profiles of several lightning strokes were analyzed and successfully compared with time profiles measured by previous researchers. Owing to information obtained while calibrating the photometers on radioactive sources in air, more accurately tuned optical filters were ordered and obtained. The experimental work was interrupted in FY 1995 when the (then) principal investigator, M. I. Buchwald, left the project.

In FY95 the new principal investigator, J. E. Borovsky, organized the LDRDrelated conference "The IGPP Workshop on the Physics of Lightning" on November 1415, 1994 in Albuquerque. There, 89 attendees discussed the properties and measurements of thunderclouds and lightning.

A new theoretical methodology for estimating the energy budget of lightning was developed. This new method leads to estimates of the efficiencies of optical emission that are higher than previous estimates.

A ground-based campaign in Fort Collins, Colorado in the summer of 1996 obtained images and photometric measurements of sprites and sprite tendrils. Broadband, intensified television cameras were used along with a high-time-resolution photometer filtered at $4278-\AA$, which is part of the $3914-\AA$ band of ionized, molecular nitrogen. These data are being used to rate the various theories about the origin of sprites above thunderclouds.

\section{Publication}

Borovsky, J. E., "Lightning Energetics: Estimates of Energy Dissipation in Channels, Channel Radii, and Channel-Heating Risetimes," to appear in J. Geophys. Res. (1997). 